\title{
Iatrogenic Iron Overload Causing Porphyria Cutanea Tarda in a Patient With a Rare Nonsense Heterozygous UROD Gene Mutation
}

\author{
Hallie B. Anderson ${ }^{1}$, Michael H. Storandt ${ }^{1}$, Rekha Kallamadi ${ }^{2}$, Dinesh Bande ${ }^{1}$, Abhishek Matta ${ }^{3,1}$ \\ 1. Internal Medicine, University of North Dakota School of Medicine and Health Sciences, Grand Forks, USA 2. Internal \\ Medicine, Sanford Health, Fargo, USA 3. Hospital Medicine, Sanford Health, Fargo, USA
}

Corresponding author: Rekha Kallamadi, rekha.kallamadi@sanfordhealth.org

\begin{abstract}
Porphyria cutanea tarda (PCT) is a rare dermatologic condition characterized by blistering of sun-exposed surfaces and elevated hepatic enzymes. It may infrequently occur as the primary presentation of underlying hemochromatosis. A 61-year-old female with anemia caused by chronic kidney disease and end-stage renal disease on hemodialysis presented with a bullous rash on her hands with associated pruritus. The rash worsened despite conservative treatment. An initial biopsy demonstrated a pauci-inflammatory cell-poor subepidermal cleft. Subsequent workup revealed elevated serum and urine porphyrins, confirming a diagnosis of PCT. Additionally, her skin was darkened and ferritin was elevated. MRI of the liver demonstrated iron overload with genetic testing negative for $C 282 Y$ or $H 63 D$ mutations, supporting a diagnosis of secondary hemochromatosis. Further genetic testing revealed that the patient had a rare heterozygous nonsense mutation of the uroporphyrinogen decarboxylase (UROD) gene, for a sequence variant designated c.616C $>$ T, which is predicted to result in premature protein termination (p.Gln206*). PCT occurs due to decreased function of $U R O D$, leading to accumulation of porphyrins causing dermatologic manifestations and liver injury. UROD is inactivated in an iron-dependent process, explaining the mechanistic link between hemochromatosis and PCT.
\end{abstract}

Review began 05/11/2021 Review ended 06/29/2021 Published 07/06/2021

(c) Copyright 2021 Anderson et al. This is an open access article distributed under the terms of the Creative Commons Attribution License CC-BY 4.0., which permits unrestricted use, distribution, and reproduction in any medium, provided the original author and source are credited.
Categories: Dermatology, Internal Medicine, Hematology

Keywords: porphyria cutanea tarda, hemochromatosis, urod mutation

\section{Introduction}

Porphyria cutanea tarda (PCT) is caused by a hepatic deficiency of uroporphyrinogen decarboxylase (UROD), an enzyme responsible for catalyzing the conversion of uropophyrinogen to coproporphyrinogen in the heme synthesis pathway. UROD deficiency leads to the accumulation of uroporphyrinogen, which is oxidized to form uroporphyrins. When exposed to sunlight, these uroporphyrins cause an immune-mediated reaction and the release of free radicals, causing the characteristic blistering lesions of PCT [1]. Most cases of PCT are classified as sporadic and are caused by viruses and substances that interfere with hepatic function, such as the hepatitis $C$ virus, human immunodeficiency virus, high alcohol consumption, and iron overload [2]. Less commonly, familial mutations in the UROD gene can cause an increased risk of PCT in conjunction with substances that reduce UROD enzyme activity [1,2]. Here, we present a case of PCT caused by an iatrogenic iron overload due to frequent iron infusions for anemia caused by chronic kidney disease (CKD) in the setting of a rare heterozygous UROD mutation.

\section{Case Presentation}

A 61-year-old female with a past medical history of anemia caused by CKD and end-stage renal disease (ESRD) on hemodialysis presented to the emergency room with acute-onset blisters on the dorsum of her hands, sparing her palms, with associated pruritus. Her pre-dialysis creatinine levels ranged from 5.99 to 8.62 $\mathrm{mg} / \mathrm{dL}$, and her red blood cell indices ranged from 2.42 to $2.62 \mathrm{M} / \mathrm{uL}$ in the month prior to the initial presentation. She was started on conservative treatment with prednisone, diphenhydramine, and triamcinolone cream. Three weeks later, the patient presented to the emergency department again for worsening of the rash (Figure 1) along with facial swelling. She was admitted, and clinical genetics and hematology-oncology were consulted. 


\section{Cureus}
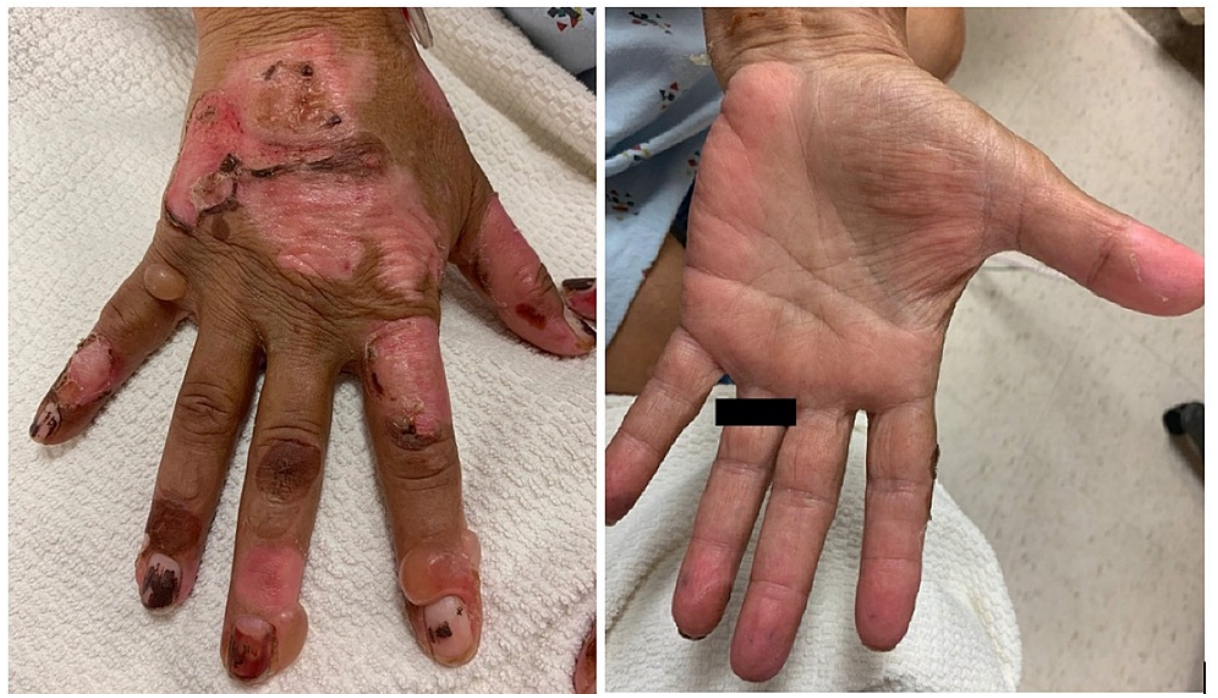

FIGURE 1: Image of the hand demonstrating multiple bullae with sparing of the palms.

A punch biopsy was performed which demonstrated thick homogeneous deposition of immunoglobulin (Ig)G, IgA, and fibrinogen within the walls of superficial dermal vessels (Figure 2). As the biopsy results were concerning for PCT, further workup was ordered which revealed elevated total porphyrins and uroporphyrins (Table 1). On examination, the patient's pigmentation was noted to be significantly darker compared to a photograph in her chart (Figure 3). Due to the patient's history of anemia and regular iron infusions every two weeks, previous iron studies were reviewed which showed a high ferritin level and total iron-binding capacity (Table 2). MRI of the liver showed iron overload and steatosis with a calculated iron concentration at $148 \mu \mathrm{mol} / \mathrm{g}$ (Figure 4). Genetic testing failed to demonstrate C282Y and H63D mutations in the HFE gene, supporting a diagnosis of secondary hemochromatosis.

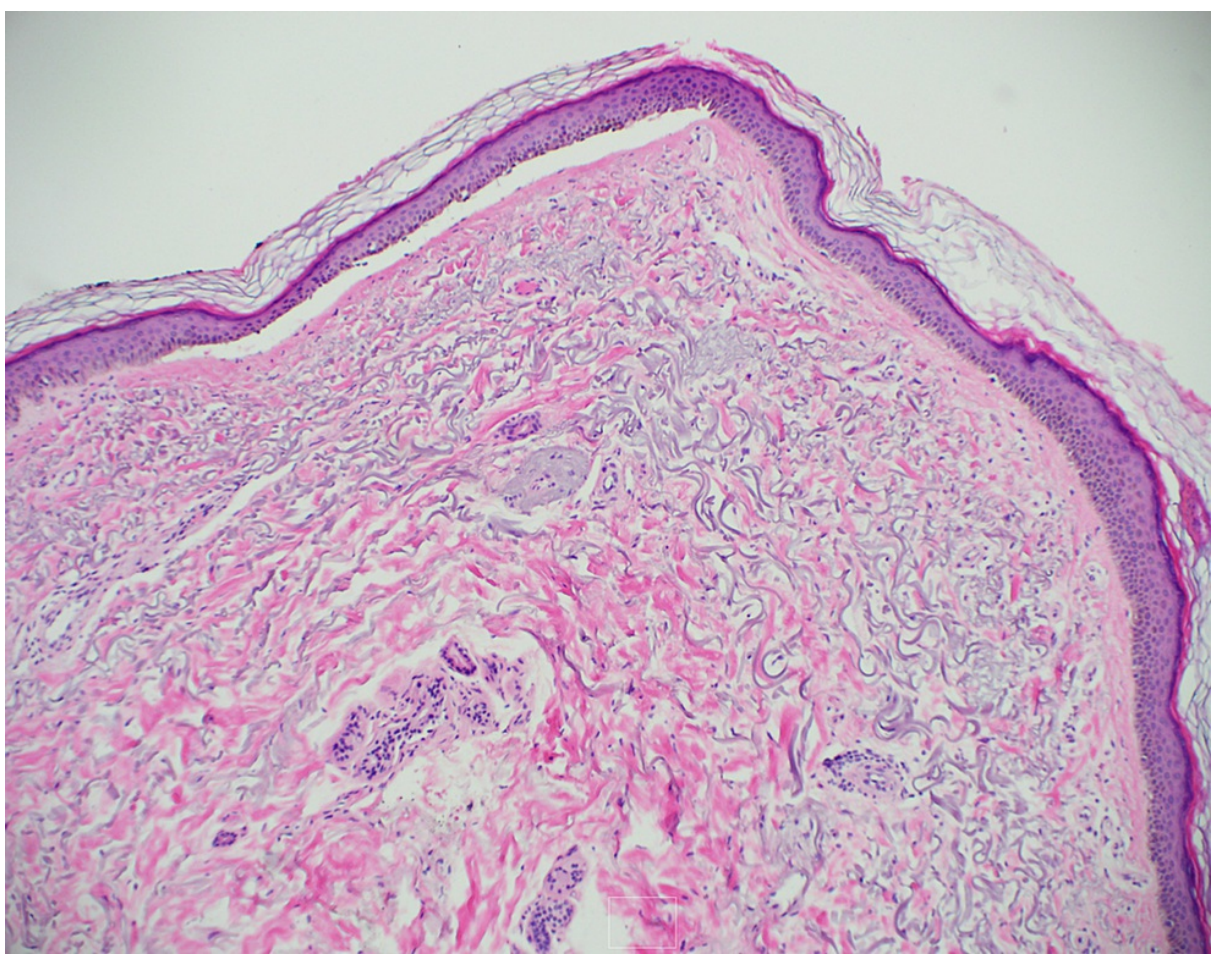

FIGURE 2: Biopsy showing thick homogeneous deposition of $\lg G, \lg A$, and fibrinogen within the walls of superficial dermal vessels.

Ig: immunoglobulin 


\section{Cureus}

Laboratory study

Serum total porphyrins

Uroporphyrin

Hexacarboxyl porphyrins

Hepatacarboxyl porphyrins

Protoporphyrin

Coproporphyrin

\section{Value}

$253 \mu \mathrm{g} / \mathrm{dL}$ (normal value $<0.1 \mu \mathrm{g} / \mathrm{dL}$ )

$34.6 \mu \mathrm{g} / \mathrm{dL}$ (normal value $<0.1 \mu \mathrm{g} / \mathrm{dL}$ )

$2.5 \mu \mathrm{g} / \mathrm{dL}$ (normal value $<0.1 \mu \mathrm{g} / \mathrm{dL}$ )

$17 \mu \mathrm{g} / \mathrm{dL}$ (normal value $<0.1 \mu \mathrm{g} / \mathrm{dL}$ )

$<0.1 \mu \mathrm{g} / \mathrm{dL}$

$<0.1 \mu \mathrm{g} / \mathrm{dL}$

TABLE 1: The patient's porphyrin studies.

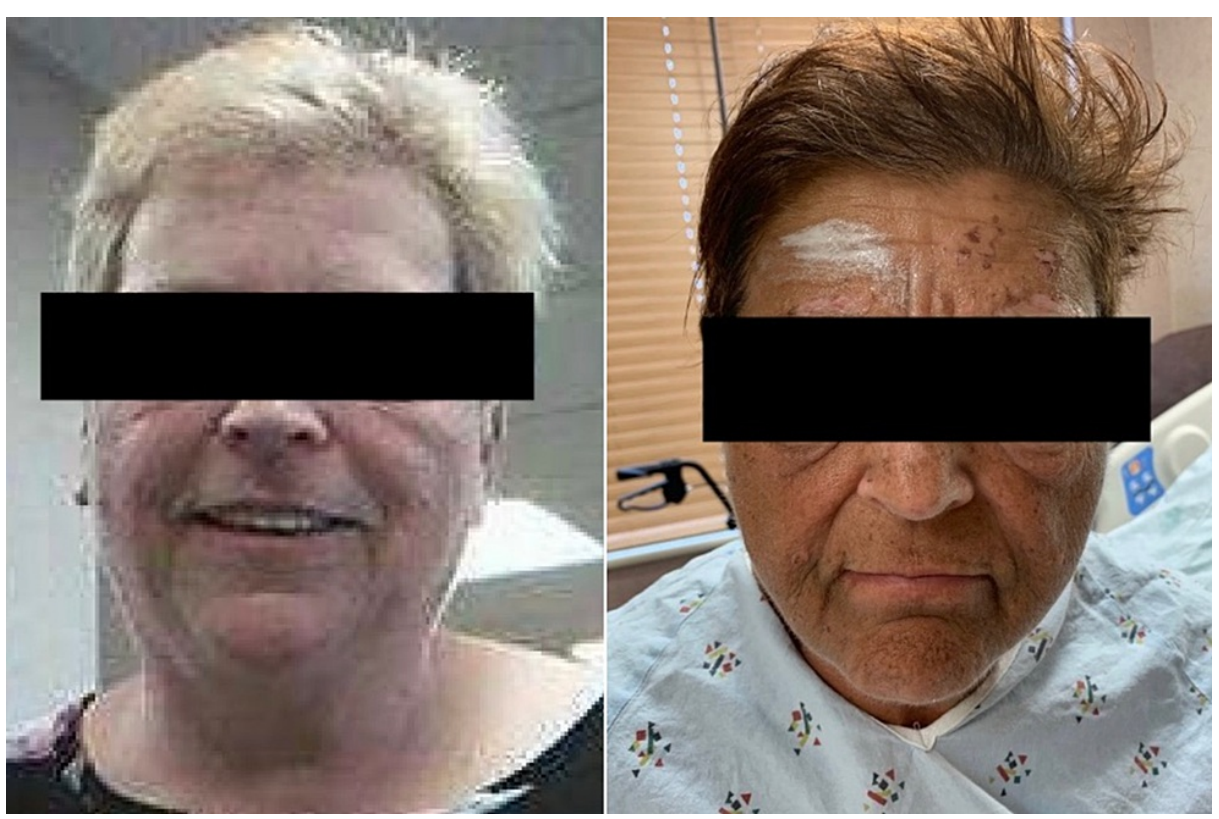

FIGURE 3: Image from the patient's chart (left) compared to an image of the patient at presentation (right) demonstrating new darkening of pigmentation.

\section{Laboratory study}

Ferritin

Percentage iron saturation

Total iron leve

Total iron-binding capacity

\section{Value}

5029 ng/mL (H)

$17 \%(\mathrm{~L})$

$28 \mu \mathrm{g} / \mathrm{dL}(\mathrm{L})$

$168 \mu \mathrm{g} / \mathrm{dL}(\mathrm{H})$

TABLE 2: The patient's iron studies. 


\section{Cureus}

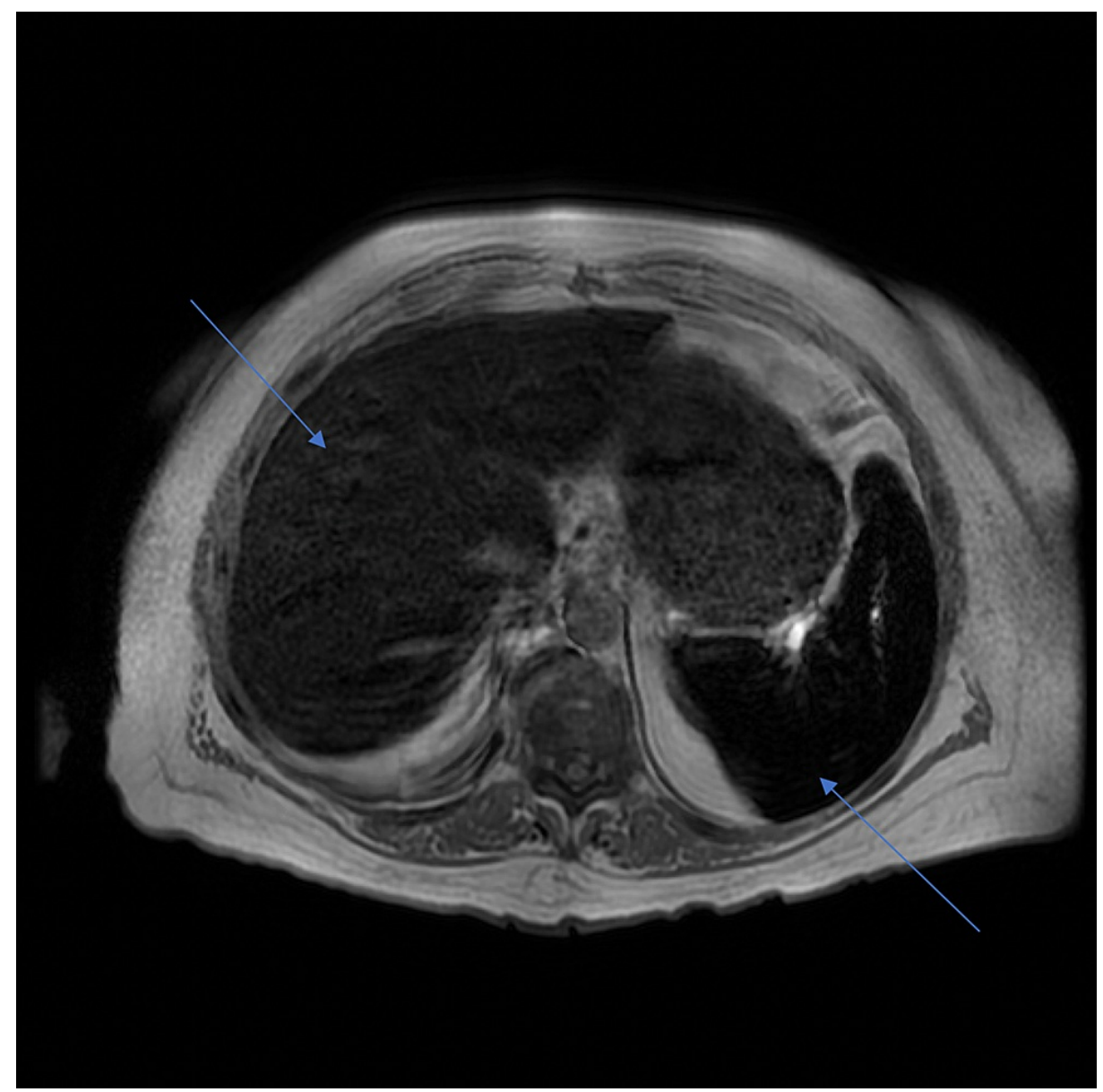

FIGURE 4: MRI of the abdomen showing iron overload in the liver and spleen. The calculated iron concentration in the liver measured 148 $\mu \mathrm{mol} / \mathrm{g}$ (normal iron concentration in the liver is less than $36 \mu \mathrm{mol} / \mathrm{g}$ ).

MRI: magnetic resonance imaging

A porphyria genome analysis revealed a rare heterozygous nonsense mutation of the $U R O D$ gene for a sequence variant designated c.616C $>\mathrm{T}$, which is predicted to result in premature protein termination (p.Gln206*). The mutation itself does not necessarily cause PCT; however, any condition that causes liver damage or iron overload can trigger PCT in the setting of decreased enzyme activity [3]. The patient had received iron infusions with dialysis every two weeks in the 11 months before presentation, with ferritin levels peaking at $5,029 \mathrm{ng} / \mathrm{mL}$ two weeks before symptom onset. This provides strong support that iron overload caused by iron infusions for anemia of CKD, with the underlying heterozygous mutation, led to the development of PCT.

The patient was started on hydroxychloroquine $1,000 \mathrm{mg}$ twice weekly. Phlebotomy was not recommended due to the patient's average hemoglobin level of $8 \mathrm{mg} / \mathrm{dL}$. Her erythropoietin dose was increased to $500 \mu \mathrm{g}$ twice weekly, and she was started on deferoxamine for iron chelation with the plan to bring her ferritin level down to less than $1,000 \mathrm{ng} / \mathrm{mL}$. Regular iron infusions with hemodialysis per treatment guidelines were discontinued to prevent further iron overload.

\section{Discussion}

PCT is a dermatologic disease marked by skin blistering on sun-exposed areas of the skin (most notably on the dorsal aspects of the hands), skin hyperpigmentation, skin thickening, and facial hypertrichosis. Patients with PCT are also at an increased risk of developing hepatocellular carcinoma [4]. Most cases of PCT are sporadic and caused by viruses and other substances that decrease hepatic function, as described previously; however, 15-50\% of PCT cases are caused by familial mutations in the UROD gene [5]. Familial PCT is inherited in an autosomal dominant manner, and most patients with familial PCT do not have an affected parent due to reduced penetrance of the gene [6]. The clinical manifestations of PCT in patients with deficient UROD enzyme activity occur when enzyme activity is below $20 \%$. This decrease in enzyme activity occurs when an individual with familial PCT is exposed to other factors that decrease hepatic function such 
as alcohol, iron overload, and hepatitis C virus. This report highlights a case of familial PCT caused by an iron overload due to regular iron infusions for the treatment of anemia in the setting of CKD. This is the first known case of a patient with a rare heterozygous nonsense mutation of the $U R O D$ gene at a sequence variant designated c.616C > T.

Patients with CKD are at an increased risk of developing iron-deficiency anemia due to increased levels of hepcidin, as it is a renally cleared peptide [7]. Iron may also be lost during dialysis. Current guidelines recommend regular intravenous iron infusions in ESRD with a maximum allowed ferritin level of $500 \mathrm{ng} / \mathrm{mL}$ [8]. Prior to the manifestation of PCT in this patient, she was receiving 4,000 $\mathrm{mg}$ of intravenous sodium ferric gluconate complex in sucrose with the dialysis every three months. One month prior to symptom onset, the patient's ferritin level increased to $5,029 \mathrm{ng} / \mathrm{mL}$. Iron overload alone decreases hepatic UROD enzyme levels, hence, the patient's iatrogenic iron overload in conjunction with a familial UROD mutation likely led to the development of PCT. Interestingly, ESRD has also been shown to be associated with PCT in rare cases likely due to decreased porphyrin excretion [9].

Treatment of PCT in patients with ESRD can be particularly challenging due to chronic anemia that is often associated with the condition. The first-line treatment of PCT traditionally involves phlebotomy with the removal of $450 \mathrm{~mL}$ of blood every two weeks and low-dose hydroxychloroquine [10]. However, phlebotomy may be contraindicated in severe cases of anemia, as was the case for this patient. The use of hydroxychloroquine in patients with ESRD may also not be effective due to inefficient porphyrin removal from the blood via dialysis. Hence, iron chelation medications such as deferoxamine have been used in cases of PCT in the setting of ESRD with a successful reduction in ferritin levels [11], as well as erythropoietin to increase hemoglobin level for subsequent phlebotomy. The patient in this case continues to take hydroxychloroquine $100 \mathrm{mg}$ twice weekly and erythropoietin $500 \mu \mathrm{g}$ every three weeks. Deferoxamine was discontinued due to improvement in ferritin levels and in preparation for therapeutic phlebotomy.

\section{Conclusions}

This case highlights the importance of recognizing the clinical manifestations of PCT, as well as factors, both environmental and iatrogenic, that may lead to its development. Particular care must be taken in patients with a family history of PCT. Treatment and management of PCT may be complicated by concomitant chronic conditions such as ESRD.

\section{Additional Information \\ Disclosures}

Human subjects: Consent was obtained or waived by all participants in this study. Conflicts of interest: In compliance with the ICMJE uniform disclosure form, all authors declare the following: Payment/services info: All authors have declared that no financial support was received from any organization for the submitted work. Financial relationships: All authors have declared that they have no financial relationships at present or within the previous three years with any organizations that might have an interest in the submitted work. Other relationships: All authors have declared that there are no other relationships or activities that could appear to have influenced the submitted work.

\section{Acknowledgements}

We would like to acknowledge Dr. Erik Heitkamp, MD, and Dr. Mahendra Gupta, MD, for their assistance in preparing this case report.

\section{References}

1. Singal AK: Porphyria cutanea tarda: recent update. Mol Genet Metab. 2019, 128:271-81. 10.1016/j.ymgme.2019.01.004

2. Handler NS, Handler MZ, Stephany MP, Handler GA, Schwartz RA: Porphyria cutanea tarda: an intriguing genetic disease and marker. Int J Dermatol. 2017, 56:e106-17. 10.1111/ijd.13580

3. Cappellini MD, Martinez di Montemuros F, Tavazzi D, et al.: Seven novel point mutations in the uroporphyrinogen decarboxylase (UROD) gene in patients with familial porphyria cutanea tarda (f-PCT). Hum Mutat. 2001, 17:350. 10.1002/humu.35

4. Liu LU, Phillips J, Bonkovsky H: Familial Porphyria Cutanea Tarda. University of Washington, Seattle, Seattle, WA; 1993-2021.

5. Aarsand AK, Boman H, Sandberg S: Familial and sporadic porphyria cutanea tarda: characterization and diagnostic strategies. Clin Chem. 2009, 55:795-803. 10.1373/clinchem.2008.117432

6. Strong A, Keller K, Merves J: Early presentation of adult-onset conditions: a dual diagnosis of hereditary hemochromatosis and porphyria cutanea tarda. Mol Genet Metab Rep. 2020, 25:100638. 10.1016/j.ymgmr.2020.100638

7. Gafter-Gvili A, Schechter A, Rozen-Zvi B: Iron deficiency anemia in chronic kidney disease . Acta Haematol. 2019, 142:44-50. 10.1159/000496492

8. Notice. Kidney Int Suppl (2011). 2012, 2:279. 10.1038/kisup.2012.37

9. Vasconcelos P, Luz-Rodrigues H, Santos C, Filipe P: Desferrioxamine treatment of porphyria cutanea tarda in a patient with HIV and chronic renal failure. Dermatol Ther. 2014, 27:16-8. 10.1111/dth.12024 


\section{Cureus}

10. Anderson KE, Goeger DE, Carson RW, Lee SM, Stead RB: Erythropoietin for the treatment of porphyria cutanea tarda in a patient on long-term hemodialysis. N Engl J Med. 1990, 322:315-7.

10.1056/NEJM199002013220507

11. Rodrigues N, Caeiro F, Santana A, Mendes T, Lopes L: Porphyria cutanea tarda in a patient with end-stage renal disease: a case of successful treatment with deferoxamine and ferric carboxymaltose. Case Rep Nephrol. 2017, 2017:4591871. 10.1155/2017/4591871 